\title{
Is Broadband over Power-lines dead?
}

\author{
Cornelis J. Kikkert \\ Electrical and Computer Engineering \\ James Cook University \\ Townsville, Australia \\ Keith.Kikkert@jcu.edu.au
}

\author{
Geoffrey D. Reid \\ Electrical and Computer Engineering \\ James Cook University \\ Townsville, Australia \\ Geoffrey.Reid@jcu.edu.au
}

\begin{abstract}
Recently there has been a significant amount of publicity about high levels of radiation from power lines using Broadband communications over Power Lines (BPL). Specific interference problems, or experimental measurements are typically cited. For smart grid, smart metering and advanced metering infrastructure applications, low data rate Power Line Communications (PLC) will be required. This paper describes a Matlab $^{\circledR}$ program for calculating the radiation and resistive losses for power lines from BPL and PLC signals. Results are presented for Single Wire Earth Return (SWER) lines, for three phase overhead lines using typical conductors mounted on crossarms and for bundled aerial conductors. These results show that depending on the cable and signal frequency, BPL and PLC can be achieved without causing significant interference.
\end{abstract}

Index Terms-PLC, BPL, Radiation, Power-line, smart grid, smart metering, AMI.

\section{INTRODUCTION}

When a power line is used for sending communication signals, there are two dominant loss factors to those signals. The first one is electromagnetic radiation. This both reduces the available signal power and causes interference to other users. The interference aspects are the most critical. The second loss factor is resistive loss, which due to the skin depth varying with frequency, causes an increasing attenuation with frequency.

There is a concern about the amount of radiation from communications signals on power lines, with amateur radio operators claiming BPL creates excessive levels of radiation $[1,2,3]$. The ACMA in conjunction with power companies have been doing experimental measurements to provide some factual data $[4,5]$. The ACMA report on the Queanbeyan BPL trial [4] reported on measurements of spectra between $150 \mathrm{kHz}$ and $30 \mathrm{MHz}$, but no conclusions are drawn to indicate if the radiation levels are acceptable or not. The ACMA report on the Hobart BPL trial [5], concludes the radiation is acceptable if FCC guide-lines are used. The situation is not clarified by the submissions to the ACMA [6] discussion paper on "The Management of Interference from Broadband over Power Line Applications", with most of the submissions reporting gut feelings rather than facts.

Finally commercial companies like MYVA[7] and MainNet [8] see BPL as having a potential to compete with ADSL and wireless broadband services, particular with governments wanting to provide broadband access to everyone [9].
It is unfortunate that these claims and reports do not distinguish between Low Voltage Overhead ( $\mathrm{LVOH}$ ) lines mounted on crossarms and Arial Bundled Conductors (ABC) or underground powerlines. This paper shows that there is a significant difference between the radiation levels from $\mathrm{LVOH}$ lines and from $\mathrm{ABC}$ or underground powerlines. To provide a rigorous basis for determining the radiation and resistive losses from powerlines, the Matlab ${ }^{\circledR}$ program described in this paper was developed. Electricity distribution companies and other communication providers can use the resulting data to determine the feasibility of power-line communications in their region.

In this paper we distinguish between PLC as a relatively low data rate application, with frequencies up to $200 \mathrm{kHz}$, primarily for use in smart grid, smart metering and advanced metering infrastructure (AMI) applications. In this paper, the term BPL is used for an application providing broadband communication access to the consumer, as an alternative to ADSL or broadband radio Internet access. BPL can require frequencies up to $100 \mathrm{MHz}$, depending on the desired system capacity.

\section{RADIATION AND LOSS MODEL}

\section{A. Theoretical Background}

The existing travelling wave model of a long wire antenna $[10,11]$ assumes that the antenna is less than $10 \lambda$ long and the current along the line is constant. This implies that no power is lost in radiation. Neither of these assumptions apply for power-lines, so that a radiation model based on fundamental equations has had to be developed.

The power radiated for an infinitesimal dipole is described in most antenna books $[10,11,12]$. The model presented in this paper cascades many of these infinitesimal dipole models to make up the whole transmission line. The power radiated by a small dipole in the far field, is dependent on the current in that dipole, $I_{o}$ and is given by (1) [10] as:

$$
P_{\text {rad }}=\eta_{0} \frac{\pi}{3}\left(\frac{l I_{0}}{\lambda}\right)^{2}
$$

where $\eta_{o}=120 \pi$. Because the line is long, $\mathrm{I}_{0}$ will not be constant. Three factors affect $\mathrm{I}_{0}$ :

1) $I_{0}$ is reduced by dissipation due to series resistance. This 
series resistance varies with frequency due to the skin depth varying with frequency.

2) $I_{0}$ is altered in phase, along the line, due to wave propagation.

3) $I_{0}$ is progressively reduced because power is radiated.

The electric field $E_{\theta}$ for this infinitesimal dipole can easily be shown $[10,11,12,13]$ to be:

$$
E_{\theta}=\frac{j \eta_{0} k I_{0} l e^{-j k l} \sin (\theta)}{4 \pi r}
$$

For a very long wire antenna, such as a power-line, the magnitude and phase of the current $I_{o}$ and $E_{\theta}$ at a position along the line is iteratively determined by considering the radiation and resistive line losses up to that point. This is then be used to determine $E_{\theta}$ caused by the infinitesimal dipole at that point. At a point along the line, the $E_{\theta}$ vector from the infinitesimal dipole is added to the cumulative $E_{\theta}$ vector, to produce the new cumulative $E_{\theta}$ vector. The power radiated is then determined by integrating the Poynting vector over a closed surface, of a sphere of radius $r$ to give [13]:

$$
P_{\text {rad }}=\frac{\pi}{\eta_{0}} \int_{0}^{\pi}|E(\theta)| r^{2} \sin (\theta) d \theta
$$

This allows the radiation loss for the whole line up to that point to be determined by using (3), so that $I_{o}$ flowing into the next infinitesimal dipole can be determined by subtracting the power lost in radiation and the resistive losses from the input power to the infinitesimal dipole. This process is then repeated to determine the $E_{\theta}$ and the power radiated by the whole line. The accuracy of this model has been verified by the authors by comparing its results to those obtained by standard equations for shorter antennae [13, 14].

\section{B. Transmission Line Parameters}

To calculate the resistive losses and radiation losses, accurate transmission line parameters need to be used. The effective line resistance $R$ and internal inductance $L_{i}$ can be shown [15] to be:

$$
\begin{aligned}
& R=\frac{\rho}{\sqrt{2 \pi a \delta}} \frac{\operatorname{ber}(q) \frac{d}{d q} \operatorname{bei}(q)-\operatorname{bei}(q) \frac{d}{d q} \operatorname{ber}(q)}{\left\{\frac{d}{d q} \operatorname{bei}(q)\right\}^{2}+\left\{\frac{d}{d q} \operatorname{ber}(q)\right\}^{2}} \Omega / \mathrm{m} \\
& \omega L_{i}=\frac{\rho}{\sqrt{2 \pi a \delta}} \frac{\operatorname{bei}(q) \frac{d}{d q} \operatorname{bei}(q)-\operatorname{ber}(q) \frac{d}{d q} \operatorname{ber}(q)}{\left\{\frac{d}{d q} b e i(q)\right\}^{2}+\left\{\frac{d}{d q} \operatorname{ber}(q)\right\}^{2}} \Omega / \mathrm{m} \\
& q=\sqrt{2} \frac{a}{\delta} \\
& \delta=\sqrt{\frac{\rho}{\pi \mu F}} \text { metres }
\end{aligned}
$$

where ber and bei are Kelvin-Bessel functions [16], $q$ is an intermediate constant given by (6), $a$ is the conductor radius, $\rho$ is the resistivity of the conductor in ohm-meters, $\delta$ is the skin depth and is given by (7), $\mathrm{F}$ is the frequency in $\mathrm{Hz}$ and $\mu$ is the magnetic permeability ( $4 \pi \times 10^{-7}$ in free space).
The line inductance for a parallel line of cylindrical geometry is then [15]:

$$
\begin{aligned}
& L=\left[4 \log _{e} \frac{D}{a}+\left(\frac{\mu_{c}}{\mu_{0}}\right)\left(\frac{L_{i}}{L_{i 0}}\right)\right] \times 10^{-7} \\
& L_{i 0}=\frac{\mu}{8 \pi} \text { and } R_{0}=\frac{\rho}{\pi \mathrm{a}^{2}}
\end{aligned}
$$

where $D$ is the distance between the centres of the conductors, $\mu_{c}$ is the magnetic permeability of the conductor and $\mu_{0}$ is the magnetic permeability of free space. $L_{i 0}$ and $R_{0}$ are the internal inductance and resistance when $a<<\delta$, i.e. at low frequency. At high frequency the right term in (8) is small and the inductance is constant. However for many communication frequencies over power-lines this is not the case and (8) must be used. The characteristic impedance of the power-line will thus vary with frequency.

The corresponding line capacitance is given on page 85 of [15] as:

$$
C=\frac{\left(\frac{\epsilon}{\epsilon_{0}}\right) \times 10^{-9}}{36 \operatorname{Cosh}^{-1}\left(\frac{D}{2 a}\right)} \text { farad } / \mathrm{m}
$$

Single Wire Earth Return power-lines are used in remote areas and are single phase lines where the ground is relied upon for the return path. For SWER lines, the distance of the ground return path below the ground level is given by Carson's equation $[17,18]$ :

$$
D=2\left(h+\sqrt{\left(\frac{\rho_{s}}{2 \pi F \mu_{0}}\right)}\right.
$$

where $h$ is the height of the SWER line above ground, $\rho_{s}$ is the soil resistivity and $\mathrm{F}$ is the signal frequency in $\mathrm{Hz}$.

For SWER lines, at $50 \mathrm{~Hz}$ the return path is typically $1 \mathrm{~km}$ below ground, while at $100 \mathrm{kHz}$ it is about $40 \mathrm{~m}$ below ground. The line capacitance and the characteristic impedance of the line will thus change significantly.

\section{Matlab ${ }^{\circledR}$ implementation.}

Matlab $^{\circledR}$ is used to calculate the resulting $E_{\theta}$ fields for these cascaded line segments, using (1) to (3) and the intermediate equations shown in $[13,14,19]$. The typical length of each line segment is $0.01 \lambda$ or $0.1 \mathrm{~km}$, whichever is the smallest, to ensure a high level of accuracy and consistent plotting of the results. For a $10 \mathrm{~km}$ line at $100 \mathrm{kHz}, 300$ line segments are used and at $100 \mathrm{MHz}, 299980$ line segments are used. Since for the results presented here, the field integration is done at 0.1 degree intervals, massive calculations are required for determining the radiation and resistive losses from a powerline at high frequencies.

Since PLC and BPL systems typically operate on relatively short power-line sections, $1 \mathrm{~km}$ and $10 \mathrm{~km}$ line lengths are used for most of the calculations presented in this paper. A $1 \mathrm{~km}$ power-line at $100 \mathrm{MHz}$ is $300 \lambda$ long, which is far in excess of the $<10 \lambda$ limit imposed by conventional antenna models.

Practical power-lines are not absolutely straight. Any small bends, as the line direction changes to follow the terrain, has a major impact on the radiation pattern [14]. Figure 1 shows the 
effect of radiation loss as the change in line direction, called wobble, in this paper is changed by a random angle with the standard deviation indicated, every $0.1 \mathrm{~km}$ for a $1 \mathrm{~km}$ long SWER line with a $1 \mathrm{MHz}$ carrier frequency. If the wobble is comparable to the spacing between the sidelobes, large changes in attenuation can result. For the radiation results presented in this paper, a $50 \mathrm{mrad}$ wobble is used as that has sufficient randomness and results in a sufficient increase in radiation, while avoiding the rapid changes in attenuation associated with a larger wobble. Introducing the wobble results in a significantly increase in radiated power. Figure 2, shows the radiation pattern of a $30 \mathrm{~km}$ long overhead line with a $1 \mathrm{MHz}$ carrier frequency and a $50 \mathrm{mrad}$ wobble. The radiation pattern is very different than that from a classical long wire antenna.

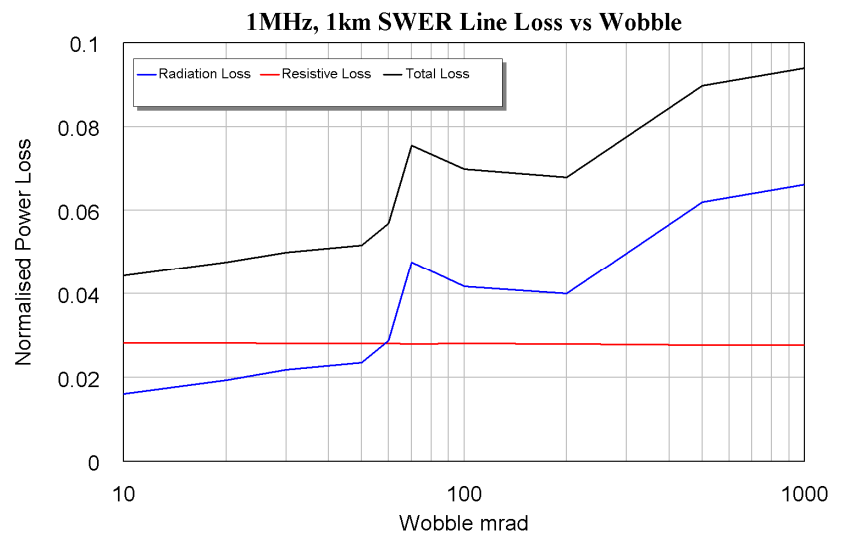

Figure 1. Radiation loss of a SWER line with bends.

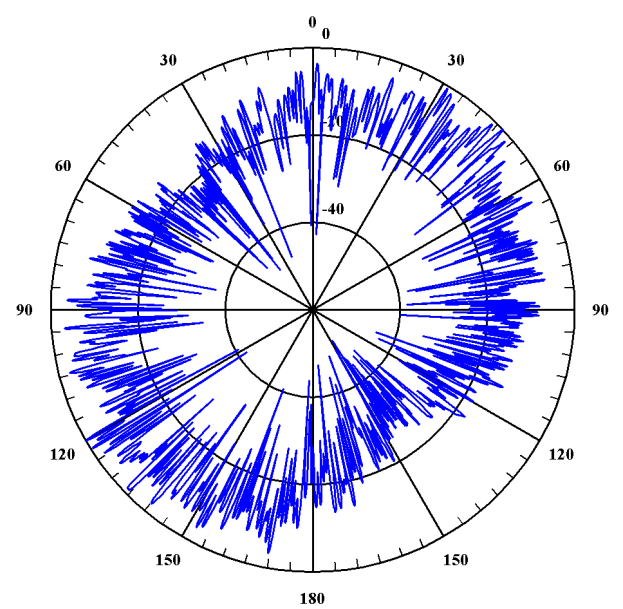

Figure 2. Radiation pattern $\mathrm{LVOH}$ line $30 \mathrm{~km}$ long with $50 \mathrm{mrad}$ wobble.

The Matlab ${ }^{\circledR}$ program calculates the skin depth (7) and uses that and (4) to determine the actual line resistance. The line inductance is calculated using (5) and (8) and that is then used to evaluate the characteristic impedance of the line using (10) and (11). The power-line is terminated in that characteristic impedance at both the source and load, to prevent reflections.
Since a typical power-line network has many bends, $\mathrm{T}$ junctions and spurs, representing it by a single line as is done here is not ideal. However, the frequency dependence of the radiation losses obtained from this Matlab ${ }^{\circledR}$ model gives a very valuable guideline on the frequency limits for the power-line configurations presented here. The model presented here assumes a perfect balance in the signal currents flowing in the pair of lines making up the BPL/PLC signal path. If the line couplers are designed to ensure that no unbalanced signals are created, then this is a valid assumption.

\section{RESULTS}

\section{A. SWER Lines}

In this study three types of power-lines are considered. The first is a SWER line consisting of a single aluminium clad steel (SCAC) cable with three $2.75 \mathrm{~mm}$ diameter strands. At typical PLC frequencies, all the currents flow in the Aluminium cladding, so for PLC frequencies, there is no difference between SCAC and Aluminium cables. The SWER line is typically $7 \mathrm{~m}$ above ground with the earth return distance varying according to (11). This is the worst case for radiation, since the distance between the line and it's return path is large and SWER lines are up to $300 \mathrm{~km}$ long.

The parameters for the SWER line obtained from the Matlab $^{\mathbb{R}}$ program are shown in figure 3. The line resistance increases significantly with frequency. Despite the earth return path depth (11) varying from close to $2000 \mathrm{~m}$ at $10 \mathrm{~Hz}$ to $20 \mathrm{~m}$ at $100 \mathrm{MHz}$, the characteristic impedance of the SWER line only varies from $690 \Omega$ at $10 \mathrm{~Hz}$ to $445 \Omega$ at $10 \mathrm{MHz}$.

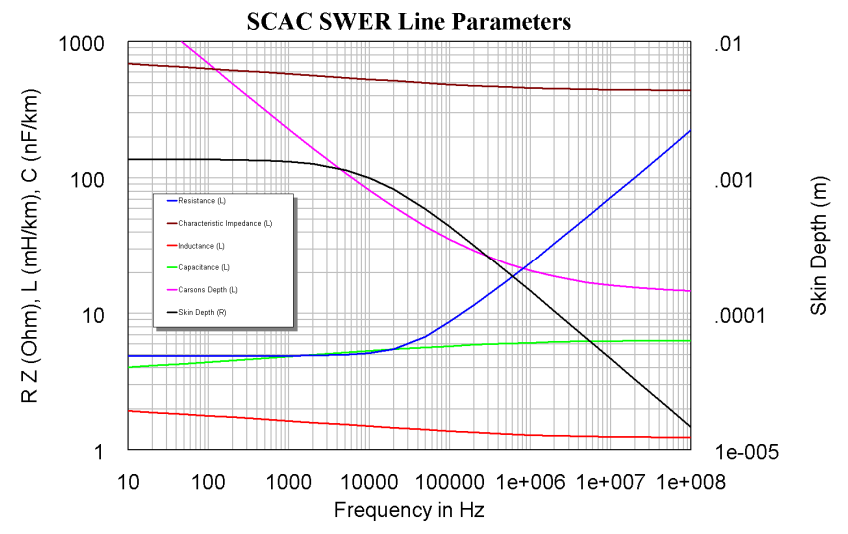

Figure 3. SWER line parameters versus frequency.

Figure 4 shows the normalised power loss from radiation and resistive losses of a $1 \mathrm{~km}$ and $10 \mathrm{~km}$ long SWER line. For the $1 \mathrm{~km}$ long line and frequencies below $1 \mathrm{MHz}$, the radiation losses are less than the resistive losses. For frequencies below $200 \mathrm{kHz}$, the radiation is small, but above this frequency there is a very rapid rise in radiation. Figure 5 shows the radiation losses versus SWER line length with the signal frequency as a parameter. SWER lines can thus be used for PLC signals up to $200 \mathrm{kHz}$ but unsuitable for BPL as the radiation losses and the resulting interference to other services will be too great. 


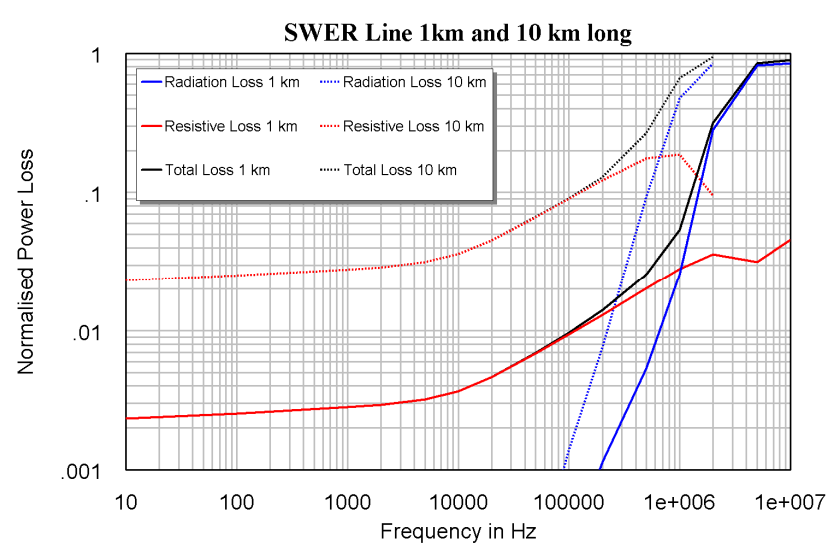

Figure 4. SWER line losses versus frequency.

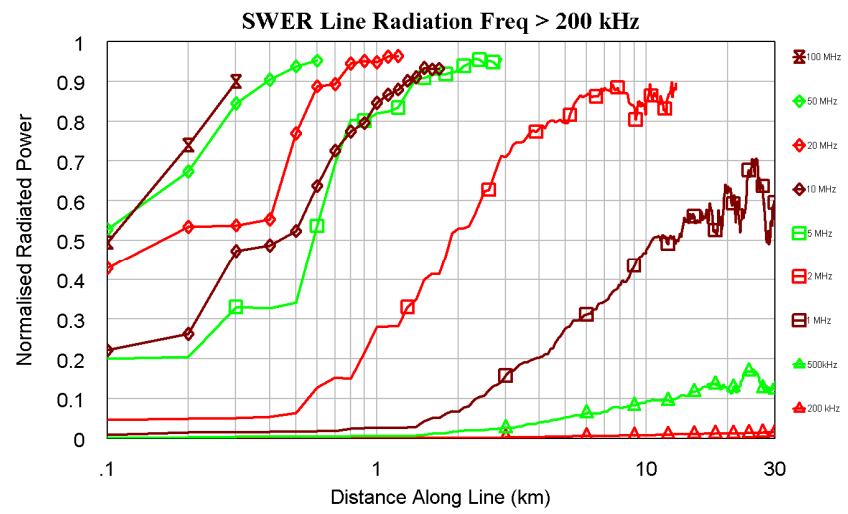

Figure 5. SWER line radiation losses versus frequency $200 \mathrm{kHz}-100 \mathrm{MHz}$.

\section{B. Overhead Lines Mounted on a Crossarm}

The second type of transmission line considered in this paper is the typical traditional open wire low voltage mains consisting of four All-Aluminium Conductor (AAC) cables each with 7 strands of $4.75 \mathrm{~mm}$ diameter mounted on a crossarm. The line consists of two sets of wires with a $550 \mathrm{~mm}$ spacing and a larger spacing between these sets of wires to accommodate the power-pole. Two of the wires with a $550 \mathrm{~mm}$ spacing are used for a balanced signal pair.

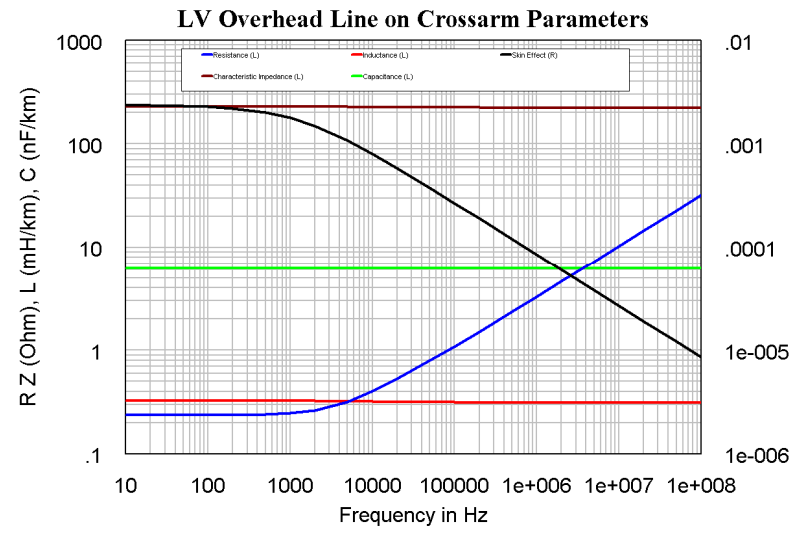

Figure 6. LV overhead line parameters versus frequency.
The parameters for the overhead line are shown in figure 6 . The characteristic impedance of the line is $225 \Omega$ and is virtually independent of frequency. There are only small variations of line inductance and capacitance with frequency.

The Low Voltage Overhead (LVOH) power-line mounted on crossarms, is the typical power-line configuration used in the USA and Australia. This type of power-line has been targeted by the American Radio Relay League (ARRL)[1] as a producer of interference due to BPL. This configuration is now a non-preferred line configuration by ERGON (The Queensland Regional Electricity Supplier).

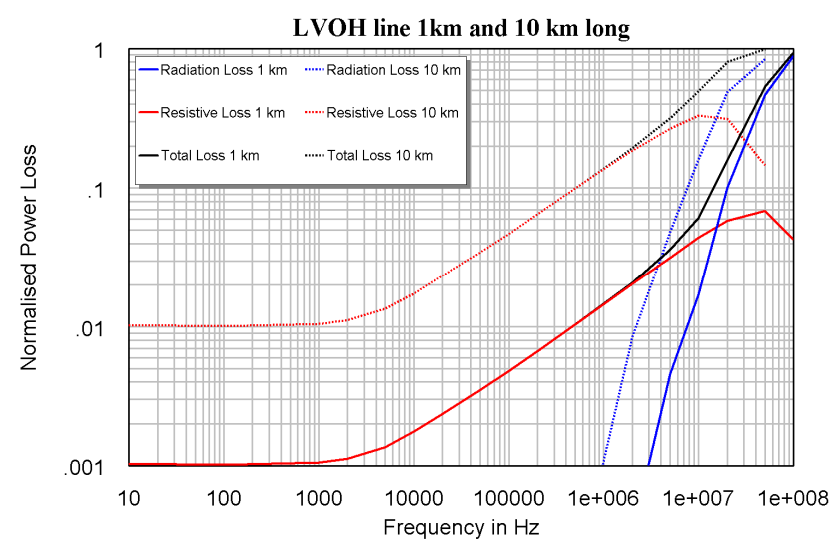

Figure 7. LV overhead line losses versus frequency.

Figure 7 shows the normalised power loss from radiation and resistive losses of a $1 \mathrm{~km}$ and $10 \mathrm{~km}$ long $\mathrm{LVOH}$ line. For the $1 \mathrm{~km}$ long line and frequencies below $15 \mathrm{MHz}$, the radiation losses are less than the resistive losses. For frequencies below $5 \mathrm{MHz}$, the radiation is small, but above this frequency there the radiation rises rapidly.

Figure 8 shows the radiation losses versus LVOH line length with the signal frequency as a parameter. These figures show that a LVOH lines can be used for PLC and PBL signals up to $5 \mathrm{MHz}$. LVOH lines will cause significant radiation for communication signals above $10 \mathrm{MHz}$, and can only be used for BPL signals above $10 \mathrm{MHz}$ if no other radio services use those frequencies, or if used HF signals are notched out of the transmitted BPL spectra.

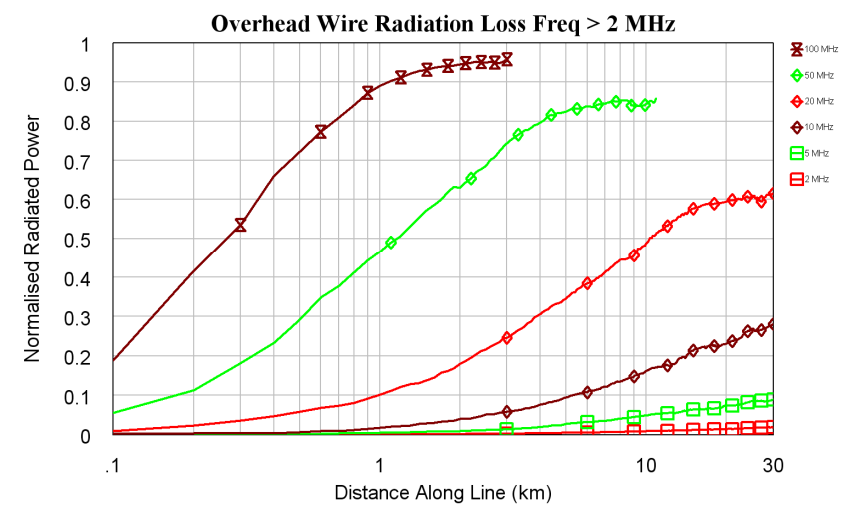

Figure 8. LV overhead line radiation losses versus frequency, 2-100 MHz. 


\section{Aerial Bundled Conductors}

The final type of transmission line considered is a Aerial Bundled Conductor ( $\mathrm{ABC})$, consisting of four insulated, compacted aluminium cables grouped together with common insulation. Each conductor is made up of 19 strands, $2.52 \mathrm{~mm}$ in diameter. Each compacted conductor is $11.4 \mathrm{~mm}$ in diameter and the spacing between the centres of the conductors is $14.9 \mathrm{~mm}$. The cable type is XDAB22AA004 from Olex [20]. This conductor is now the preferred conductor type for overhead power lines. Applying those parameters to equations (4) to (10), results in the line parameters shown in figure 9. The characteristic impedance is $30.8 \Omega$ and is virtually constant with frequency.

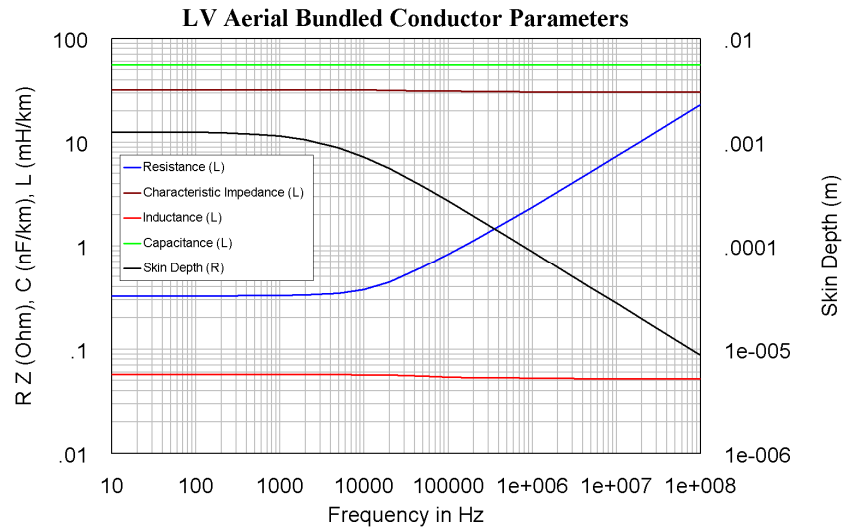

Figure 9. Bundled aerial conductor parameters versus frequency.

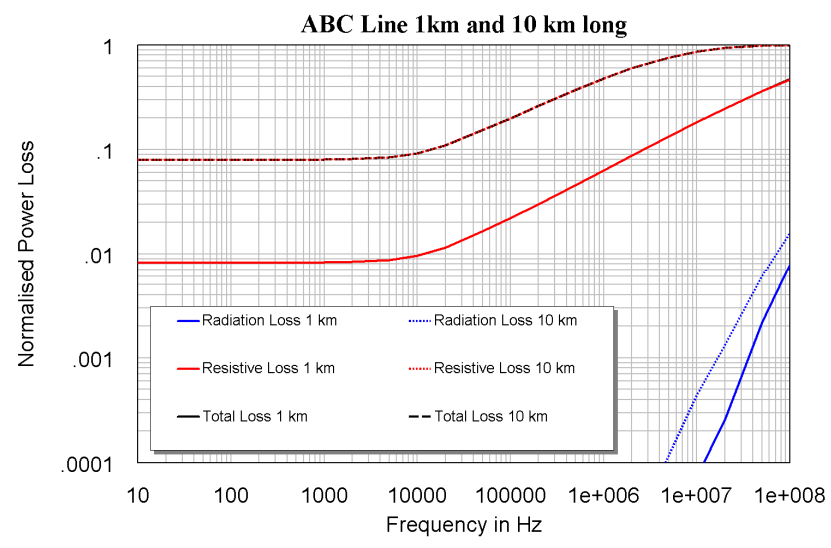

Figure 10. ABC line radiation losses versus frequency.

Figure 10 shows the normalised power loss from radiation and resistive losses of a $1 \mathrm{~km}$ and $10 \mathrm{~km}$ long $\mathrm{ABC}$ line, it show that for frequencies below $100 \mathrm{MHz}$, the radiation losses are insignificant compared with the resistive losses. Figure 10 shows that for frequencies below $10 \mathrm{MHz}$, the radiation is less than $0.2 \%$ and will thus be virtually undetectable.

Figure 11 shows the radiation losses versus line length with the signal frequency as a parameter for an $\mathrm{ABC}$ line and shows that $100 \mathrm{MHz}$ signals will only travel $13 \mathrm{~km}$ before all power is lost. The range of the BPL signals depends on the carrier frequency used, since the skin depth determines the resistive losses.

Similar results will apply for underground cables, where all the active conductors are also bundled together in one cable. $\mathrm{ABC}$ overhead lines and underground lines are thus very suitable for providing both PLC and BPL.

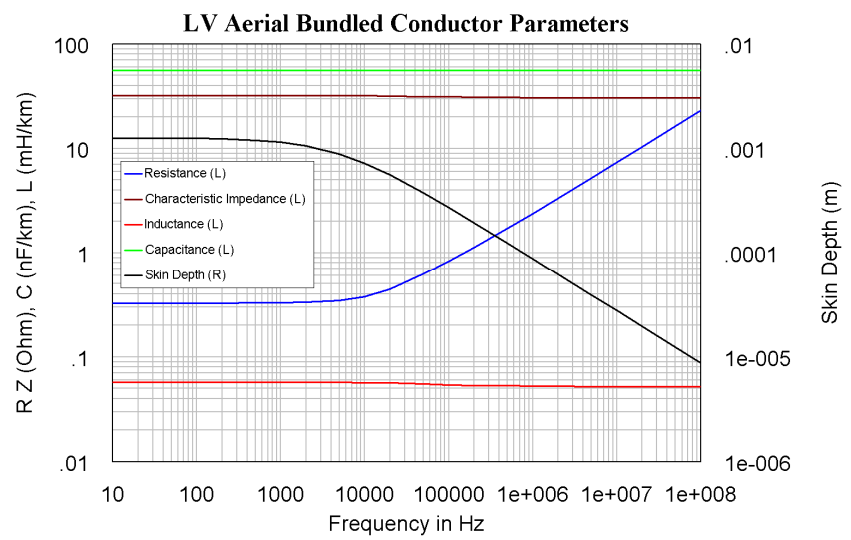

Figure 11. ABC line radiation losses at high frequency.

\section{IS BPL OR PLC DEAD?}

The results presented here show that SWER lines produce little radiation for frequencies below $200 \mathrm{kHz}$. As a result, they can be used for PLC applications, such as smart metering. However it is unlikely that any spare communication capability is available for customer internet access. Since the radiation losses dominate all other losses for frequencies above $1 \mathrm{MHz}$, BPL is not possible.

$\mathrm{LVOH}$ lines have little radiation for frequencies up to $5 \mathrm{MHz}$ and they can thus be used for both PLC and for a limited bandwidth BPL. Since radiation is the dominant loss above $15 \mathrm{MHz}$ for a $10 \mathrm{~km}$ line, the BPL frequencies should be restricted below this. In any case great care needs to be taken to ensure that any frequencies used by existing LF, MF or HF services are avoided. Whether BPL is used for LVOH lines is primarily an economic decision. If ADSL or wireless broadband are available, then the potential interference problems and the resulting reduction in available channel bandwidth may make it difficult to justify BPL.

As shown in figure 10, $\mathrm{ABC}$ and underground lines are very suitable for both PLC and BPL and cause negligible radiation. An ADSL telephone line, a ABC power-line and an underground power-line all have a similar geometry and consist of 4 conductors separated by small insulation layer, with 2 conductors being used to carry the communication signals. The main difference between these system is that for BPL all users share the same cable and thus the same channel bandwidth, while in ADSL the customer has the line for themselves. BPL is successfully used on underground powerlines in Europe [7]. In Dresden, DREWAG has a captive market in some of its BPL coverage area, since the telephone network is incapable of providing ADSL. Figure 11 shows 
high resistive losses at high frequencies. However since the skin depth determines the line resistance above $20 \mathrm{kHz}$ and the $\mathrm{ABC}$ conductor is made up of 19 strands compared to one strand for a typical ADSL line, the resistive losses for $\mathrm{ABC}$ lines are much less than for ADSL lines. Internode [20] shows that a typical ADSL line has $60 \mathrm{~dB}$ attenuation at $4.5 \mathrm{~km}$ and $300 \mathrm{kHz}$. The same length of $\mathrm{ABC}$ line has $12.6 \mathrm{~dB}$ attenuation at $100 \mathrm{MHz}$. For this line less than $1.5 \%$ of input power is radiated at $100 \mathrm{MHz}$. The $\mathrm{ABC}$ line will thus have more than 300 times the data capacity of a typical ADSL line.

PLC is very much alive for smart grid, smart metering and AMI applications, regardless of the power-line configuration used. BPL is dead for use on SWER lines. BPL is very sick for $\mathrm{LVOH}$ power-lines. BPL is healthy and competitive for $\mathrm{ABC}$ and underground power-lines.

\section{CONCLUSION}

This paper considered the radiation and resistive losses from SWER, LVOH and ABC power-lines. All these lines can be used for PLC communication at low data rate, such as is required for smart grid, smart metering and AMI applications.

SWER lines are unsuitable for Internet applications as their radiation is too large for frequencies above $200 \mathrm{kHz}$. LVOH lines mounted on crossarms will cause significant radiation for signal frequencies above $5 \mathrm{MHz}$. Higher frequency channels can be used provided no other radio communication systems are using those channels, thus tilting the economics against BPL. ABC overhead lines and underground cables, can be used for BPL applications, with little radiation, and covering larger distances than ADSL.

\section{ACKNOWLEDGMENT}

The authors would like to thank ERGON ENERGY for their support in providing the funding for this research. We also thank the technical and academic staff at James Cook University (JCU), for their assistance and encouragement in this work. The opinions expressed by the authors in this paper are not necessarily those of JCU or ERGON ENERGY.

\section{REFERENCES}

[1] Wait, P. (VK2DKN) "ARRL was correct about BPL Interference" The Wireless Institute of Australia, News release 24 June 2009. URL: https://www.wia.org.au/newsevents/news/2009/20090624-1/index.php.

[2] Harrison, R. (VK2ZRH) "BPL incapable of meeting EMC" $2009 \mathrm{VK}$ Logger Discussion Forums URL: http://www.vklogger.com./forum /viewtopic.php? $\mathrm{f}=61 \& \mathrm{t}=8632 \& \mathrm{p}=7502 \# \mathrm{p} 7502$.
[3] Williams, T. "Why broadband PLT is bad for EMC" 2005 ELMAC Services URL: http://www.elmac.co.uk/pdfs/whyPLTisbadforemc.pdf.

[4] ACMA “ACA Field Report Country Energy BPL Trial Queanbeyan NSW - February 2005" ACA URL: http://www.acma.gov.au/webwr /lib284/queanbeyan\%20trial\%20feb202005\%20final\%20public $\% 20$ report.pdf.

[5] ACMA "January 2007 ACMA measurement report on the Hobart trial" ACMA URL: http://www.acma.gov.au/webwr/lib284/measurements\% 20bpl\%20emissions\%2011_01_2007.pdf

[6] Submissions to the ACMA on discussion paper " The Management of Interference from Broadband over Power Line Applications, http://www.acma.gov.au/WEB/STANDARD/pc=PC_9240.

[7] MYVA Company web site: http://www.myva.com.au/main framecases.htm

[8] MainNet website: http://www.powerline-plc.com/applications /broadband.asp

[9] Schneider, D. "Is This the Moment for Broadband Over Power Lines: Smart grids and the push for rural connectivity propel power-line data communications" July 2009 IEEE Spectrum URL: http://spectrum. ieee.org/telecom/internet/is-this-the-moment-for-broadband-over-powerlines

[10] Balanis, A., Antenna theory: analysis and design. $2^{\text {nd }}$ edition ed. 1997: John Wiley \& Sons, Inc.

[11] Walter, C.H., Travelling Wave Antennas. 1970 ed. 1965: Dover Publications. pp 429.

[12] Ulaby, F.T., Fundamentals of Applied Electromagnetics. Fifth Edition. 1994: Pearson Prentice Hall. 456.

[13] Kikkert C. J. and Reid G, "Radiation from a Single Wire Earth Return Power Line", Electrical Energy Evolution 2008, Palm Cove, Qld Australia, 28-30 July 2008, ISBN 9780643095991, http://www.eeevolution.org/images/reid_kikkert_eee_2008.pdf.

[14] Kikkert, C. J. and G. D. Reid, "Radiation Losses from a Single Wire Earth Return Power Line with Bends". ATNAC 2008, 7-10 Dec 2008, Adelaide, South Australia.

[15] Johnson, W.C., Transmission Lines and Networks. International Student Edition 1950 : McGraw-Hill. pp 78

[16] Prudnikov, A. P.; Marichev, O. I.; and Brychkov, Yu. A. "The Kelvin Functions $\operatorname{ber}_{\mathrm{v}}(\mathrm{x}), \operatorname{bei}_{\mathrm{v}}(\mathrm{x}), \operatorname{ker}_{\mathrm{v}}(\mathrm{x})$ and $\operatorname{kei}_{\mathrm{v}}(\mathrm{x}) . " \$ 1.7$ in Integrals and Series, Vol. 3: More Special Functions. Newark, NJ: Gordon and Breach, pp. 29-30, 1990.

[17] Wang,Y., Liu, S. "A Review of Methods for Calculation of Frequencydependent Impedance of Overhead Power Transmission Lines." 2001 Proc. Natl. Sci. Counc. ROC(A) Vol 25, No. 6, 2001. pp. 329-338

[18] Deri, A.,Tevan, G., "The Complex Ground Return Plane: A Simplified Model for Homogeneous and Multi-layer Earth Return." IEEE Transactions on Power Apparatus and Systems, Vol. PAS-100, No. 8. August 1981.

[19] Kikkert, C. J., Reid, G, "Radiation and Attenuation of Single Wire Earth Return Power Lines at LF frequencies", 2009 IEEE International Symposium on Power Line Communications and its Applications, 29 March to 1 April 2009, Dresden, Germany.

[20] Olex, The 2006/7 Handbook, available from: http://storage.baselocation.com/olex.com.au/Media/Docs/.

[21] Internode Systems and Consultel, Data rates for ADSL systems versus distance to the exchange. 2007, URL: http://www.internode.on.net /residential/broadband/adsl/nakedextreme/. 